\title{
Development of a Bioconjugate Platform for Modifying the Immune Response of Autoreactive Cytotoxic T Lymphocytes Involved in Type 1 Diabetes
}

\author{
Neha Nandedkar-Kulkarni ${ }^{\dagger}$, Abhishek R. Vartak ${ }^{\ddagger}$, Steven J. Sucheck ${ }^{\ddagger}$, Katherine A. Wall ${ }^{\dagger}$, \\ Anthony Quinn§, Michael P. Morran ${ }^{\dagger}$, Marcia F. McInemey ${ }^{\star}, \dagger, \|$ \\ † Department of Medicinal and Biological Chemistry, University of Toledo, College of Pharmacy \\ and Pharmaceutical Sciences, Health Science Campus, 3000 Arlington Avenue, Toledo, Ohio \\ 43614, United States \\ ‡ Department of Chemistry and Biochemistry, University of Toledo, College of Natural Sciences \\ and Mathematics, Main Campus, 2801 West Bancroft Street, Toledo, Ohio 43606, United States \\ $\S$ Department of Biological Sciences, University of Toledo, College of Natural Sciences and \\ Mathematics, Main Campus, 2801 West Bancroft Street, Toledo, Ohio 43606, United States \\ "Center for Diabetes and Endocrine Research, University of Toledo, Health Science Campus, \\ 3000 Arlington Avenue, Toledo, Ohio 43614, United States
}

\begin{abstract}
Type 1 diabetes (T1D) is an autoimmune disorder characterized by autoimmune cell mediated destruction of pancreatic beta cells. Pancreatic beta cells are the only source of insulin in the body. T1D patients then have to depend on insulin injections for their lifetime. Insulin injection can modulate the blood sugar levels, but insulin has little effect on the autoimmune process. Altered peptide ligands (APL) derived from known autoantigens in T1D are able to induce tolerance in autoreactive cells in T1D animal models, but are currently unable to elicit this protection in humans. There is a need to improve immunogenicity of the APLs, as these short peptides can be easily degraded by enzymes in the blood. GAD546-554 is a dominant epitope recognized by autoreactive $\mathrm{T}$ cells in the nonobese diabetic (NOD) mouse model that can cause destruction of
\end{abstract}

\footnotetext{
*Corresponding Author: marcia.mcinerney@utoledo.edu. Phone: 419-383-1905.

Author Contributions

N.N.K. preformed experiments, analyzed data, and wrote the paper. A.R.V. synthesized the bioconjugates and made a contribution to writing the synthesis part of the paper. A.Q. developed the GAD546-554 specific CTL.546.L clone and altered peptide ligands.

K.A.W. was responsible for discussions on interpretation of data, and analysis of data. S.S. was responsible for bioconjugate synthesis, discussions on interpretation of data, and analysis of data. M.P.M. helped with tissue culture experiments, radiation of animals, and manuscript review. M.F.M. oversaw all of the experimentation, analysis, and writing and obtained the grant support for the paper.

The authors declare no competing financial interest.

Supporting Information

The Supporting Information is available free of charge on the ACS Publications website at DOI: 10.1021/acs.bioconj-chem.9b00332. Figure S1, Effect of GAD546-554 peptide on CTL546.L clone cells at different time points; Figure S2, MALDI-MS data of azide terminated GAD 541-554 peptide 2; Figure S3, HPLC trace of azide terminated GAD 541-554 peptide 2; Figure S4, MALDI-MS data of Pam3CysSIK4-GAD541-554 peptide conjugate 2a; Figure S5, MALDI-MS data of deprotected Pam3CysSK4-GAD541-554 peptide conjugate 2b; Figure S6, MALDI-MS data for azide terminated APL 3; Figure S7, HPLC trace of azide terminated APL 3; Figure S8, MALDI-MS data of Pam3ysSK4-APL conjugate 3a; Figure S9, MALDI-MS data of deprotected Pam3CysSK4-APL conjugate $3 \mathbf{b}(\mathrm{PDF})$
} 
beta cells. Alanine substitution at the eighth position of GAD546-554 peptide (APL9) induced tolerance in a GAD546-554 specific cytotoxic T lymphocyte clone. To improve the antigen presentation and endosomal escape of APL9, we developed a bioconjugate platform that consists of a liposome containing a bioconjugate of APL9 and toll-like receptor 2 ligand $\mathrm{Pam}_{3} \mathrm{CysSK}_{4}$ as well as an antibody against macrophage protein F4/80. APL9 bioconjugate liposome with F4/80 antibody was able to induce tolerance in a GAD 546-554 specific clone. Diabetic NOD splenocytes pretreated with APL9 bioconjugate were also not able to transfer diabetes into prediabetic NOD recipient mice. This work is beneficial to prevent T1D as an immunotherapy strategy to render autoreactive immune cells more tolerant of beta cells.

\section{Graphical Abstract}

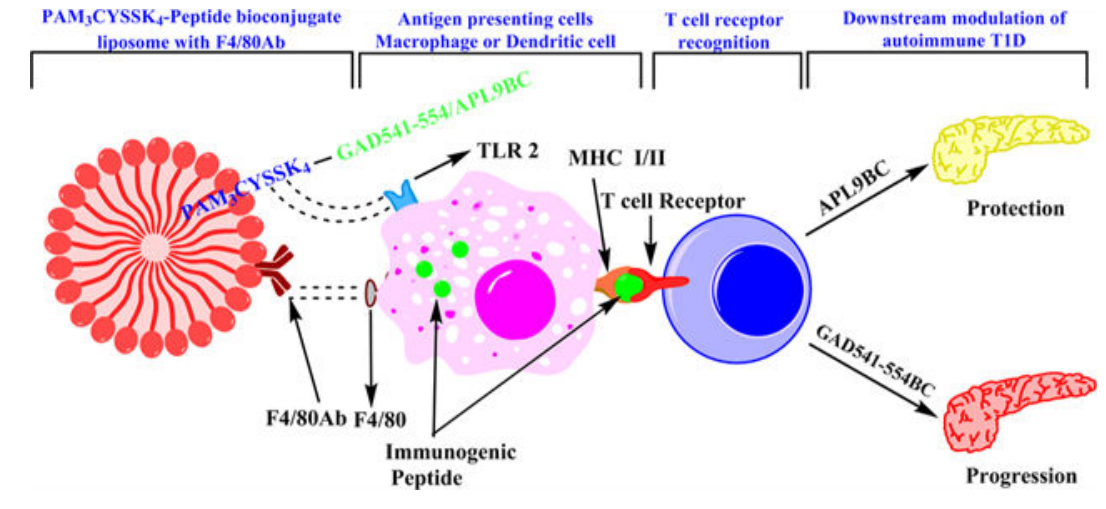

\section{INTRODUCTION}

Type 1 diabetes (T1D) is an autoimmune disorder where selfreactive immune cells cause insulin producing beta cell destruction. Due to insulin deficiency, a high blood sugar level is observed in the individual with T1D and can result in severe complications such as ketoacidosis, kidney failure, heart disease, stroke, and blindness. ${ }^{1}$ According to the Centers for Disease Control and Prevention (CDC) 2015 report, 30.3 million of people of all ages in the United States ( $9.4 \%$ of the population) had diabetes. ${ }^{2}$ The International Diabetes Federation (IDF) has estimated that 414.7 million people (8.8\%) are suffering from T1D across the globe. ${ }^{3}$ The T1D incidence rate has increased over the last 10 years. ${ }^{4}$ This indicates that whatever event triggers T1D onset is increasingly affecting individuals susceptible to T1D. ${ }^{5}$

Insulin injection is the only effective therapy available for treating T1D. Insulin injection helps to regulate blood glucose levels, but it has little effect on the autoimmunity involved in T1D. Although insulin therapy has saved countless diabetic patients from early death, there is still a need to develop a therapy targeting autoreactive immune cells involved in the beta cell destruction. Targeting autoreactive immune cells at an early stage may help to improve beta cell regeneration. It is well-known now that autoreactive $\mathrm{T}$ cells specific to islet related protein are the predominant cause of T1D. Human and animal studies have shown that CD4 and CD8 $\mathrm{T}$ cells are involved in the beta cell destruction leading to T1D. ${ }^{6,7}$ However, pancreatic beta cells express MHC class I molecules only, indicating that direct cytotoxicity 
can be mediated by CD8+ cytotoxic T lymphocytes (CTL). ${ }^{8}$ Unfortunately, there are no approved therapies available yet that selectively target these autoreactive cytotoxic $\mathrm{T}$ cells.

Insulin and glutamic acid decarboxylase 65 (GAD65) are dominant islet autoantigens during the initial progression of T1D. Autoantibodies, T helper cells, and CTLs against GAD65 were identified in prediabetic nonobese diabetic (NOD) mice as well as in recent onset T1D in humans. ${ }^{9-12}$ Beta cell specific suppression of glutamic acid decarboxylase (GAD) in NOD mice prevented diabetes because insulitis was abolished. Cells from these mice were unable to transfer diabetes in an adoptive transfer model. ${ }^{13}$ Furthermore, islets were protected when diabetic cells were adoptively transferred into the NOD transgenic mice lacking GAD on islets. This suggests that beta cell specific GAD expression is required for diabetes progression. Quinn et al. identified that GAD546-554 (SYQPLGDKV) peptide is a pathogenic CTL-inducing epitope of GAD65 that is presented by the major histocompatibility complex (MHC) class I molecule $\mathrm{K}^{\mathrm{d}}$ with position $2(\mathrm{P} 2) \mathrm{Y}$ and P9 V being considered the major anchors in the $\mathrm{K}^{\mathrm{d}}$ binding motif. ${ }^{14,15}$ GAD546-554 specific CTLs are detected in naive NOD mice, produce pro-inflammatory cytokines such as IFN $\gamma$ and TNFa upon culture with GAD546-554 peptide, and transfer islet inflammation into immunodeficient NOD.scid mice. GAD546-554 peptide is easily accessible and readily excised from GAD65 by both beta cells and professional antigen presenting cells (APCs) in vivo. ${ }^{15}$ Therefore, targeting GAD 546-554 specific CTLs can arrest beta cell specific inflammatory mechanisms.

Altered peptide ligands (APLs) or analogues of immunogenic peptides displaying a single amino acid substitution can be recognized by a $\mathrm{T}$ cell receptor (TCR) as a subtle modification in its ligand, resulting in differential T cell effector functions. APL can modulate autoreactive $\mathrm{T}$ cell responses by antagonism, anergy, or immune deviation. This suggests that APL immunotherapy can be useful to engage autoreactive T cells to lead to prevention of their autoimmune response. Various studies on animal models of autoimmunity were able to manipulate $\mathrm{T}$ cell responses and prevent tissue destruction using APLs. ${ }^{17-20}$ An APL derived from diabetes autoantigen insulin B9-23 was able to induce a protective effect in the NOD mouse model. ${ }^{21}$ However, clinical trials using the same APL failed to demonstrate efficacy of APL treatment in patients at the stage of overt disease. ${ }^{22}$ There is a necessity of developing APLs for insulin and GAD65 with improved efficiency to preserve beta cell function and prevent diabetes onset. GAD546-554, derived from GAD65, is a dominant epitope recognized by autoreactive T cells in T1D. ${ }^{14,15}$ Therefore, we evaluated the APLs derived from GAD546-554 to develop an immunotherapy targeting autoreactive T cells in T1D.

A major limitation of APL administration is their poor immunogenicity due to their short peptide sequence. Short peptides are rapidly degraded by the protease enzymes in the serum and by APCs. Enhancement of the interaction between the peptide and APCs could be a potential method for increasing APL immunogenicity. ${ }^{23,24}$ Liposomes have been used as a carrier in vaccines or immunotherapies for the effective delivery of viral, bacterial, and tumor antigens to APCs. ${ }^{25-27}$ There is also a need of an adjuvant, along with cytosol delivery of the peptide of interest, for antigen processing and presentation to CD8 T cells. ${ }^{28}$ 
Previously, toll-like receptor ligands (TLR) were used as an adjuvant and demonstrated improved peptide efficiency. ${ }^{28}$

Rockwood et al. showed that patients with T1D had increased expression of TLR2 and TLR4 on monocytes as compared to healthy control individuals. ${ }^{29} N$-Palmitoyl- $S$-[2,3bis(palmitoyloxy)-(2R,S)-propyl]-( $R$ )-cysteinyl-seryl-(lysyl)3-lysine $\left(\mathrm{Pam}_{3} \mathrm{CysSK}_{4}\right)$, a synthetic analogue of the N-terminus of Escherichia coli lipoprotein, is a well-known TLR 2 ligand. TLR 2 mediated activation and maturation of APCs is crucial for priming, effector function, and processing and presentation of antigens. $\mathrm{Pam}_{3} \mathrm{Cys}$ also controls expansion and function of regulatory T cells. ${ }^{30}$ Therefore, $\mathrm{Pam}_{3} \mathrm{CysSK}_{4}$ can be useful to activate $\mathrm{T}$ regulatory cells, leading to inhibition of autoreactive CTL. $\mathrm{Pam}_{3} \mathrm{CysSK}_{4}$, an immunogenlipopeptide construct, can also rapidly pass through the cell membrane, which helps in the formation of micellar deposits and reduced enzymatic degradation of the peptide. Thus, $\mathrm{Pam}_{3} \mathrm{CysSK}_{4}$ is used in different vaccines as a potent and safe adjuvant. ${ }^{31}$ Antibody conjugation to liposomes can be used for specific delivery of a bioconjugate (BC) to particular cells. ${ }^{32} \mathrm{~F} 4 / 80$ protein is expressed on the surface of macrophages and dendritic cells. ${ }^{33} \mathrm{~F} 4 / 80$ antibody ( $\mathrm{Ab}$ ) conjugation to liposomes can improve the possibility of the bioconjugate being processed and presented by APC. Combination of APL, $\mathrm{Pam}_{3} \mathrm{CysSK}_{4}$, F4/80 antibody, and a carrier molecule can improve APL targeting to APCs as well as APL processing and presentation by APCs. The objective of this study was to develop a bioconjugate platform which could improve immunogenicity of APL peptide immunotherapy and induce tolerance in autoreactive cells in T1D.

\section{RESULTS AND DISCUSSION}

\section{GAD546-554 Peptide Stimulates GAD546-554 Speific CTL Clone CTL.546.L.}

Rasche et al. reported that GAD546-554 specific T lymphocytes mediate beta cell death and loss of function in the NOD mouse model. ${ }^{8}$ In addition, GAD546-554 specific CTLs adoptively transferred insulitis into NOD.scid recipient mice. ${ }^{8,14,15}$ These studies indicate that the GAD546-554 epitope has a major role in T1D progression in the NOD mouse model. In this study, CTL.546.L clone, specific for the GAD546-554 peptide, was used to evaluate the efficiency of APLs. The CTL.546.L clone is a cytotoxic T lymphocyte clone specific for the GAD546-554 epitope, developed from NOD mice similar to the GAD546554 specific clone $546.14 .46 .8,15,34$

We used the GAD546-554 specific CTL clone as effector cells for evaluating the immunogenic peptide and APLs. Irradiated APCs, the M12C3.B7 B cell line or the J774 macrophage cell line, were used to present immunogenic peptide or APL on MHC molecules on their surface. The GAD546-554 peptide and APLs derived from GAD546554 are short peptides that can be presented on MHC molecules without antigen processing. The CTL.546.L clone cells produced IFN $\gamma$ upon coculture with GAD546-554 pulsed irradiated M12C3.B7 APC cells (Supplemental Figure S1). This study was performed at 24, 48 , and $72 \mathrm{~h}$ incubation time points. The CTL.546.L clone cells did not show significant changes in IFN $\gamma$ production over the time observed. Therefore, a $24 \mathrm{~h}$ incubation time point was used to perform $\mathrm{T}$ cell stimulation assays when the CTL.546.L clone cells were used as effector cells. 


\section{Screening of APLs Derived from Immunogenic Peptide GAD546-554.}

GAD546-554 derived APLs were developed by substituting an alanine group at different positions of the GAD546-554 peptide with the aim to induce tolerance in autoreactive T cells involved in T1D (Table 1).

Each of the substituted APLs was tested for IFN $\gamma$ production using CTL546.L clone cells as effector cells. Tere was no difference in the IFN $\gamma$ production between GAD546-554 and APL2 to APL8 peptide treatment. However, APL9 and APL10 treatment significantly decreased IFN $\gamma$ production by the autoreactive CTL.546.L clone cells (Figure 1A). CTL. 546.L clone cells were derived from NOD mouse primary $\mathrm{T}$ cells and expanded by stimulating with GAD546-554 peptide. CTL.546.L clone cells release IFN $\gamma$ on stimulation with GAD546-554 (Supplementary Figure S1, Figure 1A and 1B). We observed variation in the IFN $\gamma$ release dependent on the CTL.546.L clone cell passage number and frequency of stimulation. We consistently observed a significant increase in the IFN $\gamma$ fold release upon stimulation with GAD546-554 peptide, although there was variation in the IFN $\gamma$ concentration. Therefore, we used untreated and GAD546-554 peptide as negative and positive controls, respectively, in all the experiments related to the CTL.546.L clone. APL9 treatment also reduced the CTL.546.L effector cell function of TNFa secretion (Figure 1C).

When APL9 or APL10 were used in combination with GAD546-554, only APL9 treated CTL546.L clone cells did not secrete significant IFN $\gamma$ (Figure 1B) and TNFa (Figure 1C) compared to the immunogenic GAD546-554 peptide alone. APL10 treatment did not significantly reduce the IFN $\gamma$ release response in the presence of GAD546-554 peptide.

APL9 and APL10 have alanine substitution respectively at the eighth and ninth position of GAD546-554. Non-responsiveness with APL9 treatment indicates that substitution of lysine with alanine at the eighth positon of GAD546-554 can significantly affect the stimulation of the GAD546-554 specific CTL clone. Moreover, APL9 has shown a significant decrease in autoreactive CTL.546.L clone activity even in the presence of the immunogenic peptide GAD546-554 and thus can be used for developing an immunotherapy for T1D. Due to APL9's potential to induce tolerance in the autoreactive $\mathrm{T}$ cell clone, a bioconjugate platform was developed using the APL9 peptide.

\section{Design and Development of the Bioconjugate Platform.}

The major limitation of short peptide immunotherapy is their poor immunogenicity. Short peptides require an adjuvant for targeting APCs. Toward this, and to prevent peptide degradation, liposomes were used as a carrier in the bioconjugate platform (Figure 2). ${ }^{35}$

$\mathrm{Pam}_{3} \mathrm{CysSK}_{4}$, a TLR2 ligand, was conjugated with a short peptide according to the Hossain et al. $\mathrm{Pam}_{3} \mathrm{CysSK}_{4}$-peptidebioconjugate method (Figure 3). ${ }^{36} \mathrm{Pam}_{3} \mathrm{CysSK}_{4}$ acts as a lipid anchor for the peptide in the liposomal construct as well as an adjuvant. TLR2 is present on the surface of macrophages and dendritic cells, and $\mathrm{Pam}_{3} \mathrm{CysSK}_{4}$ and TLR2 binding leads to activation and maturation of macrophages and dendritic cells. This helps in processing and presentation of the peptide to T lymphocytes (Figure 2). We assume that the bioconjugate can bind to the APCs with either TLR2 ligand $\mathrm{Pam}_{3} \mathrm{CysSK}_{4}$ or F4/80 antibody or both targeting molecules and then is internalized and processed. When the GAD546-554 peptide 
was incorporated into the bioconjugate, the epitope peptide was not efficiently processed by APCs and presented on MHC class I or class II molecules (data not shown). Therefore, peptides in the bioconjugates were made with a linker sequence of GAD541-545 (GTTMVSY-QPLGDKV) prior to the epitope peptides to give a GAD541-554 BC sequence or a corresponding GAD541-554 APL9BC.

In addition, the F4/80 $\mathrm{Ab}$ was conjugated on the liposomal construct for specifically targeting macrophage and dendritic cells. F4/80 protein is present on the surface of macrophages and dendritic cells. ${ }^{37-39}$ Therefore, the bioconjugate liposome with F4/80 antibody on the surface binds to F4/80 expressing macrophages and dendritic cells. F4/80 antibody conjugation on the surface of liposome can increase the probability of bioconjugate presentation to macrophages and dendritic cells. $\mathrm{Pam}_{3} \mathrm{CysSK}_{4}$ in the bioconjugate can help to process the peptide conjugated with it. The peptide later will be taken up for antigen processing and presentation through MHC class I or class II. Similar bioconjugate liposomal constructs have demonstrated promising findings in developing anticancer vaccines. ${ }^{36,40} \mathrm{We}$ developed $\mathrm{Pam}_{3} \mathrm{CysSIK}_{4}$-GAD541-554 immunogenic bioconjugate liposomes (GAD541554BC) first to observe if immunogenic bioconjugate liposomes can accelerate the effector activity of autoreactive GAD546-554 specific CTLs.

\section{Synthesis of $\mathrm{Pam}_{3} \mathrm{CysSK}_{4}$-Peptide Conjugates (2b and $3 \mathrm{~b}$ ).}

$\mathrm{Pam}_{3} \mathrm{CysSIK}_{4}$-DBCO 1 was synthesized as previously described. ${ }^{36}$ Azide terminated peptides ( 2 and $\mathbf{3}$ ) were synthesized using a CEM Liberty Blue automated microwave peptide synthesizer (CEM Corporation, Matthews, NC). Compound $\mathbf{1}$ was dissolved in MeOH:DCM (1:1, $2 \mathrm{~mL})$ along with peptides $\mathbf{2}$ and $\mathbf{3}$ under $\mathrm{N}_{2}$ at room temperature (RT) (Figure 3). The azide-alkyne cycloaddition (AAC) reaction was monitored using MALDI (2,5-dihydroxybenzoic acid (DHB) was used as a matrix) and appeared complete after $12 \mathrm{~h}$. The side chain deprotection was achieved using a TFA cocktail (TFA:DCM:TES; 50:50:0.5), and the final bioconjugate was precipitated out of the solution using cold ether.

\section{Activity of GAD541-554BC Liposomes against Autoreactive Immune Cells Involved in T1D.}

GAD541-554BC with or without F4/80 Ab (40 $\mu \mathrm{g} / \mathrm{mL})$ treatment improved the CTL.546.L clone IFN $\gamma$ production significantly compared to GAD546-554 peptide treatment (Figure 4). This indicates that the peptide generated from the bioconjugate construct can be recognized by the autoreactive CTL.546.L clone with accelerated effector activity. Moreover, the liposomal peptide construct at $40 \mu \mathrm{g} / \mathrm{mL}$ (peptide concentration in the bioconjugate) concentration with $\mathrm{F} 4 / 80 \mathrm{Ab}$ conjugation is a better $\mathrm{T}$ cell stimulant than peptide alone.

EX vivo, efficiency of the bioconjugate liposomes was evaluated in a proliferation assay and the IFN $\gamma$ secreting cell assay. Prediabetic NOD mouse (6-8 week old) splenocytes were treated with carboxyfluorescein succinimidyl ester (CFSE), a proliferation dye, for determining the proliferation index of splenocytes using flow cytometry. CFSE treated prediabetic NOD mice splenocytes were later incubated with GAD541-554BC with or without F4/80 Ab for $96 \mathrm{~h}$. GAD541-554BC treatment increased the proliferation index of prediabetic NOD mouse splenocytes (Figure 5A). 
GAD541-554BC with or without F4/80 Ab treatment had a similar effect on spleen cell proliferation. The spleen has a mixture of T cells, B cells, macrophages, and dendritic cells. Macrophages and dendritic cells have more exposure to bioconjugates in a spleen suspension compared to peripheral blood. Therefore, F/80 Ab conjugation was still used in later experiments with the aim to improve targeting of bioconjugates to macrophages and dendritic cells. To determine whether proliferating splenocytes are T cells, an IFN $\gamma$ secreting cell ELISPOT assay was performed. Prediabetic NOD mice splenocytes treated with GAD541-554BC showed increased IFN $\gamma$ secreting cells (Figure 5B). Thus, proliferating cells in the CFSE proliferation assay could be IFN $\gamma$ secreting cells.

Proliferation and IFN $\gamma$ ELISPOT assays confirm the bioconjugate delivered peptide is being processed and presented by NOD mice APCs and that NOD splenocytes can detect the peptide derived from the bioconjugate construct. In addition, these findings indicate that prediabetic NOD mice have GAD546-554 specific immune cells. Further, prediabetic NOD mice were treated with GAD541-554BC to test if peptide presented from bioconjugate can be recognized by autoreactive T cells in vivo. GAD541-554BC treatment did not trigger diabetes at an early time point in NOD mice. However, we observed a significant increase in IFN $\gamma$ secreting cells in GAD541-554BC with F4/80 Ab treated mice (Figure 5C). The combination of TLR2 ligand and F4/80 Ab can increase the chances of the peptide being processed and presented by APCs. Therefore, we used bioconjugates with F4/80 Ab liposomes for further studies.

\section{Activity of APL9 Bioconjugate (APL9BC) Liposomes with F4/80 Ab against Autoreactive T Cells Involved in T1D.}

The immunogenic bioconjugate construct studies indicated that the bioconjugate construct improves the immunogenic peptide activity. Therefore, we used the same bioconjugate construct and replaced GAD541-554 peptide with APL9 peptide, which was capable of eliminating or reducing autoreactive T cell activity. J774 macrophage cells were treated with APL9BC with F4/80 Ab and later cocultured with CTL 546.L clone cells. APL9BC with $\mathrm{F} 4 / 80 \mathrm{Ab}$ significantly reduced IFN $\gamma$ production compared to GAD541-554BC with F4/80 $\mathrm{Ab}$ treatment (Figure 6).

CTL.546.L. clone cells were cocultured with APCs, treated with the combination of GAD541-554BC with F4/80 Ab and APL9BC with F4/80 Ab, to determine if APL9BC can antagonize the effect of GAD541-554BC. APL9BC with F4/ $80 \mathrm{Ab}$ was able to reduce CTL.546L clone cell stimulation even in the presence of immunogenic GAD541-554BC (Figure 6). APL9BC with F4/80 Ab treatment to CTL.546.L clone cell has shown that the peptide derived from APL9BC can induce nonresponsiveness in the autoreactive GAD546554 specific clone. CTL.546.L clone cells did not show any stimulation upon treatment with blank liposomes and F4/80 antibody liposomes. This indicates that the immunogenic activity of the GAD541-554BC liposome with F4/80 and the nonresponsiveness to the APL9BC liposome with F4/80 were due to the peptide attached to the Pam3CysSK4. The F4/80 antibody conjugation and liposome carrier are assisting in target-specific delivery of the short peptide to dendritic cells and macrophages. APL9BC liposome with F4/80 Ab were tested in different proportions with immunogenic GAD541-554BC liposome with F4/80 Ab. 
This suggests that the APL9BC liposome can induce nonresponsiveness (tolerance) in the autoreactive cytotoxic T lymphocytes even in the presence of immunogenic GAD541554BC liposome with F4/80 Ab. We have not performed direct binding studies of APL9 binding to class I MHC to show whether the antagonism is at the level of MHC binding or at the $\mathrm{T}$ cell receptor level. The fact that the APL9BC can prevent responses to GAD541554BC at a ratio of 1:1 (Figure 6) suggests that the antagonism is more likely at the level of the $\mathrm{T}$ cell receptor.

\section{Activity of APL9BC with F4/80 Ab in Diabetes Adoptive Transfer Model.}

A diabetes adoptive transfer model was used to evaluate if APL9BC treated diabetic splenocytes can transfer diabetes into irradiated young nondiabetic NOD mice. Diabetic NOD mice splenocytes can cause diabetes when adoptively transferred in young irradiated NOD mice within 4-5 weeks time (Figure 7A). Diabetic NOD mice splenocytes treated with $\mathrm{F} 4 / 80 \mathrm{Ab}$ liposomes or GAD541-554BC with F4/80 Ab were also able to transfer diabetes in irradiated young NOD mice. However, APL9BC with F4/80 Ab treated diabetic splenocytes did not transfer diabetes into young irradiated nondiabetic NOD mice. In addition, APL9BC with F4/80 Ab treated splenocyte recipient had a significantly higher percentage of insulin positive islets compared to untreated, blank liposome and GAD541554BC with F4/80 Ab treated splenocyte recipient islets (Figure 7B). Although insulitis was observed in the APL9BC with F4/80 Ab treated splenocyte recipients, autoreactive immune cells did not cause significant insulin producing beta cell destruction. Similarly, NBI-6024, an APL for insulin B 9-23, protected NOD mice from diabetes even in the presence of autoreactive T cells specific for other autoantigens related to T1D. ${ }^{21}$ This suggests that targeting one of the autoantigen specific autoreactive $\mathrm{T}$ cells may be enough to protect the NOD mice from diabetes progression.

APL9BC with F4/80 Ab can induce nonresponsiveness in the autoreactive immune cells in NOD mice to prevent the transfer of T1D. In addition, APCs can efficiently process the bioconjugate and present the peptide to T cells. The fact that APL9BC liposome with F4/80 $\mathrm{Ab}$ prevented diabetes transfer in adoptive diabetes transfer experiments indicates that GAD65 is a dominant autoantigen involved in the T1D disease progression. These data also confirm previous findings that loss of expression of GAD on the islets of NOD mice was protective against diabetes development, and associated adoptive transfer experiments were not able to transfer diabetes. ${ }^{13}$ Previous animal models and in vitro human studies have demonstrated that APLs derived from insulin B 9-23 or GAD 65 can prevent T1D or develop tolerance in autoreactive T cells involved in the human T1D, but these APLs failed to demonstrate significant improvement in human T1D treatment. ${ }^{21,41,42}$ The APL against insulin B (9-23) peptide (NBI-6024), containing two alanine substitutions at the 16 and 19 positions, was able to induce nonresponsiveness in murine or human T-cells specific for insulin B 9-23 and also protected NOD mice from developing diabetes. ${ }^{21,43}$ However, NBI-6024 did not show any effect on the insulin producing beta cell function and their insulin requirement in the new onset individuals with T1D. ${ }^{44}$ One of the reasons could be that NBI-6024 is a short peptide. Short peptides are known to have poor immunogenicity and a short half-life in vivo. Therefore, NBI-6024 might not be able to reproduce the results in the human as compared to the in vitro human cell studies and in vivo animal studies. It 
would be interesting to observe the effect of NBI-6024 on conjugation with $\mathrm{PAM}_{3} \mathrm{CYSSK}_{4}$ and F4/80 Ab liposome.

The liposomal bioconjugate construct has shown improved activity of the pathogenic peptide in the GAD546-554 specific CTL clone stimulation assay and prevented diabetes progression in NOD mouse adoptive transfer model using APL9. The combination of altered peptide ligand, TLR2, and antibody targeting was used for the first time to alter autoreactive $\mathrm{T}$ cell immune responses. The peptide in the bioconjugate liposome can be easily replaced with another antigen derived peptide. Therefore, the bioconjugate liposome platform can be used to target different autoantigens involved in T1D.

\section{MATERIALS AND METHODS}

All fine chemicals and solvents were obtained from Acros Organics, Fisher Scientific, AlfaAesar, and Sigma-Aldrich. Preloaded Wang resins and Fmoc amino acids were obtained from AAPPTEC, AnaSpec, or Chem-Impex International, Inc. Flash column chromatography was performed on silica gel (230-400 mesh) obtained from Sorbent Technologies using solvents as received. ${ }^{1} \mathrm{H}$ NMR spectra were obtained using a Bruker Avance III $600 \mathrm{MHz}$ spectrometer using residual $\mathrm{CHCl}_{3}$ or $\mathrm{MeOD}$ as internal references. ${ }^{13} \mathrm{C}$ NMR were recorded at $125 \mathrm{MHz}$ using residual $\mathrm{CHCl}_{3}$ or $\mathrm{MeOD}$ as internal references. Matrix assisted laser desorption/ionization (MALDI) was performed on a Bruker Microflex benchtop instrument. Dihydroxybenzoic acid was used as a matrix for MALDI analysis.

\section{Synthesis of Azide Terminated GAD 65 Peptides and APL (2 and 3).}

GAD65 peptide and APL were synthesized on a CEM Liberty Blue Automated Microwave Peptide Synthesizer (CEM Corporation, Matthews, NC) using the Fmoc strategy. The peptide synthesis was performed on a $100 \mu \mathrm{mol}$ scale with help of $N, N^{\prime}$ diisopropylcarbodiimide (DIC) and ethyl (hydroxyimino)cyanoacetate (Oxyma) as coupling agents. Deprotection of the $N_{\mathrm{a}}$-Fmoc group was accomplished by treatment with $25 \%$ piperidine in dimethylformamide (DMF). For the final coupling, 6-azido-hexanoic acid was used on the solid phase synthesizer. Following completion of the synthesis, both cleavage and side-chain deprotection reactions were manually performed using a modified reagent $\mathrm{K}$ cocktail (88\% TFA, 3\% thioanisole, 5\% ethanedithiol, $2 \%$ water, and 2\% phenol). The peptides were then precipitated out and washed using ice-cold anhydrous tert-butyl ether. The precipitated and washed peptides were then dissolved in 25\% acetonitrile in water for analysis and purification. Prior to preparative scale HPLC purification, analytical HPLC (Beckman System Gold) was performed using a Vydac C18 column to identify the peptide. The purity of the crude preparation was checked by gradient elution (5-60\% acetonitrile) with a single peak at $214 \mathrm{~nm}$ (solvent $\mathrm{A}=0.085 \%$ TFA in water; solvent $\mathrm{B}=98 \%$ acetonitrile and $0.085 \%$ TFA in water). The appropriate fractions were collected and subjected to mass spectrometry. The analysis was performed using a MALDI-TOF/TOF mass spectrometer (Model No. 4800; AB SCIEX, Framingham, MA). Following HPLC purification (Waters Corporation) using a Vydac preparative C18 column, the purity (>95\%) was further assessed by analytical HPLC and mass spectrometry as performed above. The peptides were lyophilized and stored at $-80^{\circ} \mathrm{C}$. GAD 541-554 Peptide 2: MALDI-TOF: [M 
$+\mathrm{H}$ ] $\mathrm{m} / \mathrm{z}$ calcd for $\mathrm{C}_{71} \mathrm{H}_{116} \mathrm{~N}_{19} \mathrm{O}_{23} \mathrm{~S}, 1634.810$; found 1634. 995. APL 3: MALDI-TOF: [M

$+\mathrm{Na}] \mathrm{m} / \mathrm{z}$ calcd for $\mathrm{C}_{68} \mathrm{H}_{108} \mathrm{~N}_{18} \mathrm{O}_{23} \mathrm{SNa}, 1600.770$; found 1600.228.

\section{Synthesis of Pam $_{3}$ CysSK $_{4}$-GAD 65/APL Peptide Conjugates (2a and 3a).}

Compound 1 (3.4 mg, $1.5 \mu \mathrm{mol})$ and azide terminated peptides [ 2 (1.7 mg, $1.5 \mu \mathrm{mol}), 2$ (2.5 $\mathrm{mg}, 1.5 \mu \mathrm{mol}), 3$ (2.4 mg, $1.5 \mu \mathrm{mol})]$ were dissolved in anhydrous DCM:MeOH mixture (1:1, $2 \mathrm{~mL}$ ) and stirred under $\mathrm{N}_{2}$ at RT. Complete consumption of starting material was observed using MALDI along with the appearance of $\mathrm{m} / \mathrm{z}$ peak of cycloaddition product after $12 \mathrm{~h}$. The reaction mixture was concentrated and redissolved in $\mathrm{CHCl}_{3}(4 \mathrm{~mL})$. The organic layer was washed with water $(2 \times, 4 \mathrm{~mL})$ and dried over $\mathrm{Na}_{2} \mathrm{SO}_{4}$. The organic layer was evaporated to afford cycloaddition product as pale white solid. 2a: MALDI-TOF: [M+H] $\mathrm{m} / z$ calcd for $\mathrm{C}_{194} \mathrm{H}_{326} \mathrm{~N}_{31} \mathrm{O}_{44} \mathrm{~S}_{2}, 3860.945$; found 3861.610. 3a: MALDI-TOF: [M + h] $\mathrm{m} / \mathrm{z}$ calcd for $\mathrm{C} 191 \mathrm{H} 318 \mathrm{~N} 30 \mathrm{O} 44 \mathrm{~S} 2,3803.850$; found 3803.185

\section{Synthesis of Deprotected Pam ${ }_{3}$ CysSK $_{4}$-GAD 65/APL Peptide Conjugates (2b and 3b).}

The cycloaddition products $(1.5 \mu \mathrm{mol})$ were dissolved in cleavage cocktail of DCM:TFA:TES (50:50:0.5, $1 \mathrm{~mL}$ ) and stirred for 40 min at RT under $\mathrm{N}_{2}$ atmosphere. The DCM was evaporated, and the remaining reaction mixture was added to cold ether $\left(-10^{\circ} \mathrm{C}\right.$, $5 \mathrm{~mL}$ ). The solution was kept at $-20{ }^{\circ} \mathrm{C}$ overnight for precipitation of target compound. The precipitate was centrifuged followed by two washings with cold ether and dried under high vacuum to obtain the desired compound. $2 \mathbf{b}$ (5 mg, 96\% over 2 steps) MALDI-TOF: [M + $\mathrm{H}] \mathrm{m} / \mathrm{z}$ calcd for $\mathrm{C}_{170} \mathrm{H}_{285} \mathrm{~N}_{31} \mathrm{O}_{36} \mathrm{~S}_{2}, 3403.372$; found $3403.862 .3 \mathbf{b}$ (4.5 mg, 89\% over 2 steps) MALDI-TOF: [M+ H] m/z calcd for $\mathrm{C}_{167} \mathrm{H}_{279} \mathrm{~N}_{30} \mathrm{O}_{36} \mathrm{~S}_{2}$, 3347.286; found 3347.477.

\section{Bioconjugate Liposome with or without F4/80 Antibody Formulation.}

Stock solutions were prepared of dipalmitoylphosphatidylcholine (DPPC), cholesterol, and 1,2-distearoyl-sn-glycero-3-phosphoethanolamine- $N$-[maleimide-(polyethylene glycol) (DSPE-PEG-MAL). Aliquots from stock solution were mixed to obtain a lipid solution of 15 $\mathrm{mM}$ in a total volume of $2 \mathrm{~mL}$. Four different batches of liposomes were prepared. The first batch involved only DPPC (80\%) and cholesterol (20\%) for blank liposome formulation. The second one contained DPPC (80\%), cholesterol (20\%), and DSPE-PEG-MAL (1\%) for F4/80 antibody liposomes. The third batch had DPPC (80\%), cholesterol (20\%), and bioconjugate (GAD546-554, GAD541-554, or APL9) in different concentrations (10, 20, 40,100 , and $200 \mu \mathrm{g} / \mathrm{mL}$ ) for bioconjugate liposome without $\mathrm{F} 4 / 80$ formulation. The fourth batch had DPPC (80\%), cholesterol (20\%), DSPE-PEG-MAL (1\%), and bioconjugate (GAD546-554, GAD541-554, or APL9) in different concentrations (10, 20, 40, 100, and $200 \mu \mathrm{g} / \mathrm{mL}$ ). Liposomes were formulated by the extrusion method with $100 \mathrm{~nm}$ polycarbonate membrane as previously described. ${ }^{25}$

\section{Surface Functionalization of Liposomes with F4/80 Antibody.}

Surface functionalized targeted liposomes were prepared using a protein thiolation and conjugation protocol. ${ }^{45,46}$ Briefly, F4/80 antibodies (Ab) in PBS (pH 7.5) were added to the succinimidyl 3-(2-pyridyldithio)propionate (SPDP) solution (20 $\mathrm{mM}$ in ethanol) and stirred for $1 \mathrm{~h}$ at RT. Excess SPDP (10:1 molar ratio) was removed using a Sephadex G-50 spin 
column. The filtrate was treated with DTT (15 mM in PBS) at room temperature for $30 \mathrm{~min}$ to reduce SPDP. Excess DTT was removed using a G-50 spin column. The filtrate containing thiolated antibodies was added to liposomal batches 2 and 4 containing DSPEPEG-MAL and stirred overnight to obtain liposome-F4/80 antibody conjugate. The liposomal solution was taken in an Eppendorf tube along with $1 \mathrm{~mL}$ PBS and vortexed. The suspension was centrifuged at $14000 \mathrm{rpm}$ for $5 \mathrm{~min}$ at $4{ }^{\circ} \mathrm{C}$. The supernatant was discarded, and the pellet was washed with PBS buffer two times. The surface conjugation was confirmed by fluorescence microscopy, and conjugation efficiency was determined by Bradford assay. Efficiency for antibody conjugation to liposome was 70\%, determined using 50,100 , or $200 \mu \mathrm{g}$ of antibody in $1 \mathrm{~mL}$ of liposome suspension. One-hundred micrograms ofF4/80 antibody in $1 \mathrm{~mL}$ of liposome suspension gave the optimal immunological results. Therefore, $100 \mu \mathrm{g}$ antibody per $1 \mathrm{~mL}$ of liposome suspension was used for antibody conjugated liposome formulation.

\section{Mice.}

NOD/LtJ mice were purchased from The Jackson Laboratory (Bar Harbor, ME) and bred and maintained at the University of Toledo (Toledo, $\mathrm{OH}$ ) under specific-pathogen-free conditions in the Department of Laboratory Animal Resources. All animal experiments were performed according to approved guidelines of the National Institutes of Health, and protocols were approved by the Institutional Animal Care and Use Committee (\#N105461)

\section{Cells.}

GAD546-554 specific cytotoxic T lymphocyte clone CTL.546.L was generated as previously described ${ }^{15}$ following immunization of NOD mice with GAD546-554 (Invitrogen, Carlsbad, CA). The M12C3.B7 ( $\mathrm{K}^{\mathrm{d}}$ ) cell line (ATCC, Manassas, VA), J774 cell line (ATCC, Manassas, VA), and CTL.546.L clones were cultured in a complete media containing RPMI 1640 complete medium supplemented with glutamine (Hyclone, South Logan, UT), $1 \%$ penicillinstreptomycin (Mediatech Inc., Manassas, VA), 10\% fetal bovine serum (FBS, Atlanta Biologicals, Flowery Branch, GA), 1\% sodium pyruvate (Life Technology, Grand Island, NY), $1 \%$ nonessential amino acids (Mediatech Inc., Herndon, VA), and 0.001\% 2-mercaptoethanol (Life Technology, Grand Island, NY). TheCTL.546.L clone cells were stimulated every 2 weeks with GAD546-554 peptide treated irradiated (1200 rads) prediabetic male NOD mice splenocytes $\left(20 \times 10^{6}\right.$ cells). To obtain the splenocyte suspension, spleens were harvested from the euthanized prediabetic 6-8 week old male NOD mice. A single cell suspension of splenocytes was prepared by crushing the spleens between two frosted sterile slides. The splenocyte suspension was centrifuged at $1000 \mathrm{rpm}$ for $10 \mathrm{~min}$. The splenocyte pellet was treated with $1 \mathrm{~mL}$ ACK lysis buffer (Lonza, Walkersville, MD) for $3 \mathrm{~min}$, and its activity was blocked by adding $10 \mathrm{~mL}$ of FBS containing complete media. Cells were spun down at $1000 \mathrm{rpm}$ for $10 \mathrm{~min}$. The supernatant was discarded, and the cell pellet was resuspended in the $10 \mathrm{~mL}$ complete media and irradiated at 1200 rads. Irradiated splenocytes $\left(20 \times 10^{6}\right.$ cells $)$ were pulsed with GAD546554 peptide $(10 \mu \mathrm{g} / \mathrm{mL}$, Ohio Peptide, Powell, $\mathrm{OH})$ for $3-4 \mathrm{~h}$ before coculturing with CTL. 546.L clone. Every 3 days later, recombinant human IL-2 (10 ng/mL Peprotech, Rocky Hill, $\mathrm{NJ}$ ) was added in the CTL546.554 clone cell suspension to maintain them in culture. 


\section{CTL Stimulation Assay Using Peptide as an Antigen.}

Antigen presenting cells $\left(0.5 \times 10^{5}\right.$ cells per well), M12C3.B7 cells (irradiated), were treated with $10 \mu \mathrm{g} / \mathrm{mL}$ GAD546-554 or altered peptide ligands (Ohio Peptide, Powell, OH) for 3-4 h. Pulsed antigen presenting cells were cocultured with the CTL546.L clone cells $\left(2 \times 10^{5}\right.$ cells per well) for 24-72 h. Supernatant was collected for analyzing IFN $\gamma$ (Murine IFN $\gamma$ ELISA kit, Biolegend, San Diego, CA) and TNFa ( murine TNFa ELISA kit, Peprotech, Rocky Hill, NJ) production. An IFN $\gamma$ and TNFa ELISA was performed pursuant to the manufacturer's instructions. Cytokine production was reported as the fold change from the untreated cells.

\section{CTL Stimulation Assay Using Bioconjugate Liposomes.}

Antigen presenting cells $\left(0.5 \times 10^{5}\right.$ cells per well), J774 macrophage cell line cells, were treated with the bioconjugate (GAD541-554 or APL9) liposomes with or without F4/80 Ab in different concentrations of bioconjugate $(10,20,40,100$, and $200 \mu \mathrm{g} / \mathrm{mL})$ for $3-4 \mathrm{~h}$. Pulsed antigen presenting cells were cocultured with the CTL546.L clone cells $\left(2 \times 10^{5}\right.$ cells per well) for 24-72 h. Supernatant was collected for analyzing IFN $\gamma$ (Murine IFN $\gamma$ ELISA kit, Biolegend, San Diego, CA) and TNFa (Murine TNFa ELISA kit, Peprotech, Rocky Hill, NJ) production. An IFN $\gamma$ and TNFa ELISA was performed pursuant to the manufacturer's instructions. Cytokine production was reported in the fold change from the untreated cells.

\section{IFN $\gamma$ ELISPOT.}

Spleens were harvested from the euthanized prediabetic 6-8 week old male NOD mice. A single cell suspension of splenocytes was prepared as mentioned above. An IFN $\gamma$ ELISPOT assay was performed using murine immunospot IFN $\gamma$ single color ELISPOT kit (Cellular Technology Limited (CTL), Cleveland, OH). Prediabetic NOD female mice splenocytes $(1 \times$ $10^{6}$ cells per well) were treated with the $40 \mu \mathrm{g} / \mathrm{mL}$ GAD 541-554 bioconjugate liposome with or without $\mathrm{F} 4 / 80 \mathrm{Ab}$ for $24 \mathrm{~h}$ in an IFN $\gamma$ ELISPOT kit provided 96 -well plate at $37^{\circ} \mathrm{C}$. A subsequent assay was performed according to the IFN $\gamma$ ELISPOT kit manufacturer's protocol. IFN $\gamma$-secreting spots were detected by ELISPOT reader.

\section{T Cell Proliferation Assay.}

Prediabetic male NOD mice (6-10 week old) splenocytes were labeled with CFSE using CellTrace CFSE Cell Proliferation Kit. Splenocytes were treated with $5 \mu \mathrm{M}$ CellTrace CFSE dye in sterile PBS for $20 \mathrm{~min}$ at $37^{\circ} \mathrm{C}$. Five times the original volume of complete media was added to the labeled splenocyte suspension and incubated for $5 \mathrm{~min}$ to stop the CellTrace CFSE dye activity. Cells were washed with the complete media twice and used for a stimulation assay. Labeled splenocytes $\left(5 \times 10^{5}\right.$ cells/well) were treated with $40 \mu \mathrm{g} / \mathrm{mL}$ GAD541-554 bioconjugate with or without F4/80 Ab at $37{ }^{\circ} \mathrm{C}$ for $96 \mathrm{~h}$. Splenocyte cell divisions were monitored and enumerated by flow cytometry using an FACS Caliber instrument. Splenocytes were gated for lymphocytes using forward scatter and side scatter. The proliferation index was determined using FCS Express 4 flow research edition software. 


\section{NOD Mice Immunization.}

GAD541-554 bioconjugate liposome (10 nmol per mouse) with or without F4/80 Ab in 100 $\mu$ L PBS suspension was injected intraperitoneally into 6 week old female NOD mice for 3 consecutive weeks. Immunized mice were monitored for hyperglycemia using AlphaTrak blood glucose monitoring system (Abbott Laboratories, Chicago, IL). Spleen cells were harvested at the end of the seventh week of immunization for analyzing IFN $\gamma$ secreting spots using a murine IFN $\gamma$ ELISPOT kit.

\section{Splenocyte Adoptive Transfer into Irradiated Young Nondiabetic NOD Recipients.}

For adoptive transfer, 12-15 week old NOD female mice were screened for hyperglycemia. Three new-onset diabetic NOD mice with blood glucose more than $250 \mathrm{mg} / \mathrm{dl}$ were used for adoptive transfer. Upon donor sacrifice, spleens were harvested, and single cell splenocyte suspensions were prepared. Sixty million splenocytes were treated with blank liposomes, with F4/80 Ab or GAD541-554BC liposomes with F4/80 Ab (40 $\mu \mathrm{g} / \mathrm{mL})$, or with APL9BC liposomes with $\mathrm{F} 4 / 80 \mathrm{Ab}(40 \mu \mathrm{g} / \mathrm{mL})$ for $24 \mathrm{~h}$ at $37^{\circ} \mathrm{C}$. Twenty million treated splenocytes from donors were adoptively transferred through intraventricular injection into the 6-8 week old irradiated (700 rads) female nondiabetic NOD mice. Six mice received untreated splenocytes; six mice received blank liposomes with F4/80 Ab treated splenocytes, and six mice received GAD541-554BC liposomes with F4/80 Ab treated splenocytes. Six mice received APL9BC liposomes with F4/80 Ab treated splenocytes. Random blood glucose was monitored, and they were sacrificed once they become diabetic. A mouse with blood glucose $\geq 250 \mathrm{mg} / \mathrm{dl}$ was considered as a diabetic.

\section{Immunofluorescence Microscopy.}

Pancreas tissue was harvested from the diabetic adoptive transfer recipient mice as well as from nondiabetic adoptive transfer recipients and fixed in 10\% formalin w/v (Fisher Scientific, Fair Lawn, NJ) at $4{ }^{\circ} \mathrm{C}$ overnight. Paraffin embedded sections were deparaffinized and rehydrated before antigen retrieval by microwaving in $10 \mathrm{mM}$ citrate buffer $\mathrm{pH}$ 6.0. Sections were blocked with $1 \%$ BSA in PBS for 30 min and stained overnight at $4{ }^{\circ} \mathrm{C}$ with anti-insulin produced in a guinea pig (1:1500, Sigma, St Louis, MO). The next day, primary antibody labeled sections were washed and stained with secondary antiguinea pig IgG FITC (1:500, Invitrogen) for 1-2 $\mathrm{h}$ at room temperature. After washing, sections were mounted with DAPI-Fluoromount G (Sigma, St Louis, MO) following dehydration and imaged on a Nikon TS fluorescent microscope.

\section{Statistics.}

All data are presented as mean \pm SEM and were analyzed using the unpaired Student's $t$ test, one-way ANOVA followed by Tukey's multiple comparison test, or two-way ANOVA followed by Tukey's multiple comparison test, depending on the number of variables. The survival curve was analyzed using Log-Rank analysis. $P \leq 0.05$ was considered significant. Male animals were selected randomly (unless stated otherwise) for experiments considering the age of the animal. All tests were performed using GraphPad Prism 5.04 software. 


\section{Supplementary Material}

Refer to Web version on PubMed Central for supplementary material.

\section{ACKNOWLEDGMENTS}

This work was supported by the National Institutes of Health (NIH) National Institute of Diabetes and Digestive and Kidney Diseases (NIDDK) Grant R15-DK-103196-01 (M.F.M.), NIH General Medicine Grant R15GM094734 (K.W. and S.S.), Interdisciplinary Research Initiation Award Program, University of Toledo (M.M., S.S., K.W., and A.Q.), and the Frederic and Mary Wolfe Fund for Diabetes Research-Pharmacy.

\section{REFERENCES}

(1). ADA (2009) Diagnosis and classification of diabetes mellitus. Diabetes Care 32 (Suppl 1), S62S67. [PubMed: 19118289]

(2). Centers for Disease Control and Prevention, U.S. Deptartment of Health and Human Services (2017) Atlanta, GA, pp 1-20 (https://www.cdc.gov/diabetes/pdfs/data/statistics/national-diabetesstatistics-report.pdf).

(3). Unwin N, Whiting D, Gan D, Jacqmain O, and Ghyoot G (2009) International Diabetes Federation, IDF Diabetes Atlas, 4th edition, chapter 2, pp 22-37 (https://www.idf.org/e-library/ epidemiology-research/diabetes-atlas/21-atlas-4th-edition.html).

(4). Karvonen M (2006) Incidence and trends of childhood Type 1 diabetes worldwide 1990-1999. Diabetic Med. 23, 857-66. [PubMed: 16911623]

(5). Van Belle TL, Coppieters KT, and von Herrath MG (2011) Type 1 diabetes: etiology, immunology, and therapeutic strategies. Physiol. Rev. 91, 79-118. [PubMed: 21248163]

(6). Haskins K, and McDuffie M (1990) Acceleration of diabetes in young NOD mice with a CD4+ islet-specific T cell clone. Science 249, 1433-6. [PubMed: 2205920]

(7). Wang B, Gonzalez A, Benoist C, and Mathis D (1996) The role of CD8+ T cells in the initiation of insulin-dependent diabetes mellitus. Eur. J. Immunol. 26, 1762-1769. [PubMed: 8765018]

(8). Rasche S, Busick RY, and Quinn A (2009) GAD65-Specific Cytotoxic T Lymphocytes Mediate Beta-Cell Death and Loss of Function. Review of Diabetic Studies: RDS. 6, 43-53. [PubMed: 19557295]

(9). Tisch R, Yang XD, Singer SM, Liblau RS, Fugger L, and McDevitt HO (1993) Immune response to glutamic acid decarboxylase correlates with insulitis in non-obese diabetic mice. Nature 366, 72-5. [PubMed: 8232539]

(10). Kaufman DL, Clare-Salzler M, Tian J, Forsthuber T, Ting GS, Robinson P, Atkinson MA, Sercarz EE, Tobin AJ, and Lehmann PV (1993) Spontaneous loss of T-cell tolerance to glutamic acid decarboxylase in murine insulin-dependent diabetes. Nature 366, 69-72. [PubMed: 7694152]

(11). Nepom GT (2003) Conversations with GAD. J. Autoimmun. 20, 195-8. [PubMed: 12753802]

(12). Mallone R, Kochik SA, Laughlin EM, Gersuk VH, Reijonen H, Kwok WW, and Nepom GT (2004) Differential Recognition and Activation Thresholds in Human Autoreactive GAD-Specific T-Cells. Diabetes 53, 971-977. [PubMed: 15047612]

(13). Yoon JW, Yoon CS, Lim HW, Huang QQ, Kang Y, Pyun KH, Hirasawa K, Sherwin RS, and Jun HS (1999) Control of autoimmune diabetes in NOD mice by GAD expression or suppression in beta cells. Science 284, 1183-7. [PubMed: 10325232]

(14). Quinn A, McInerney MF, and Sercarz EE (2001) MHC Class I-Restricted Determinants on the Glutamic Acid Decarboxylase 65 Molecule Induce Spontaneous CTL Activity. J. Immunol. 167, 1748-1757. [PubMed: 11466400]

(15). Busick RY, Aguilera C, and Quinn A (2007) Dominant CTL-inducing epitopes on GAD65 are adjacent to or overlap with dominant Th-inducing epitopes. Clin. Immunol. 122, 298-311. [PubMed: 17174605] 
(16). Severe S, Gauvrit A, Vu AT, and Bach JM (2007) CD8+ T lymphocytes specific for glutamic acid decarboxylase 90-98 epitope mediate diabetes in NOD SCID mouse. Mol. Immunol. 44, 295060. [PubMed: 17336387]

(17). Sloan-Lancaster J, and Allen PM (1996) Altered Peptide Ligand-Induced Partial T Cell Activation: Molecular Mechanisms and Role in T Cell Biology. Annu. Rev. Immunol. 14, 1-27. [PubMed: 8717505]

(18). Karin N, Mitchell DJ, Brocke S, Ling N, and Steinman L (1994) Reversal of experimental autoimmune encephalomyelitis by a soluble peptide variant of a myelin basic protein epitope: $\mathrm{T}$ cell receptor antagonism and reduction of interferon gamma and tumor necrosis factor alpha production. J. Exp. Med. 180, 2227-37. [PubMed: 7525850]

(19). Nicholson LB, Greer JM, Sobel RA, Lees MB, and Kuchroo VK. (1995) An altered peptide ligand mediates immune deviation and prevents autoimmune encephalomyelitis. Immunity 3 , 397-405. [PubMed: 7584131]

(20). Ford ML, and Evavold BD (2003) Regulation of Polyclonal T Cell Responses by an MHC Anchor-Substituted Variant of Myelin Oligodendrocyte Glycoprotein 35-55. J. Immunol. 171, 1247-1254. [PubMed: 12874212]

(21). Alleva DG, Gaur A, Jin L, Wegmann D, Gottlieb PA, Pahuja A, Johnson EB, Motheral T, Putnam A, Crowe PD, et al. (2002) Immunological characterization and therapeutic activity of an alteredpeptide ligand, NBI-6024, based on the immunodominant type 1 diabetes autoantigen insulin Bchain (9-23) peptide. Diabetes 51, 2126-34. [PubMed: 12086942]

(22). Walter M, Philotheou A, Bonnici F, Ziegler A-G, and Jimenez R (2009) No Effect of the Altered Peptide Ligand NBI-6024 on $\beta$-Cell Residual Function and Insulin Needs in New-Onset Type 1 Diabetes. Diabetes Care 32, 2036-2040. [PubMed: 19690081]

(23). Jackson DC, O’Brien-Simpson N, Ede NJ, and Brown LE (1997) Free radical induced polymerization of synthetic peptides into polymeric immunogens. Vaccine 15, 1697-1705. [PubMed: 9364702]

(24). Tam JP (1996) Recent advances in multiple antigen peptides. J. Immunol. Methods 196, 17-32. [PubMed: 8841440]

(25). Sarkar S, Salyer A(C)D, Wall KA, and Sucheck SJ (2013) Synthesis and immunological evaluation of a MUC1 glycopeptide incorporated into 1-rhamnose displaying liposomes. Bioconjugate Chem. 24, 363-375.

(26). Mallick AI, Singha H, Chaudhuri P, Nadeem A, Khan SA, Dar KA, and Owais M (2007) Liposomised recombinant ribosomal L7/L12 protein protects BALB/c mice against Brucella abortus 544 infection. Vaccine 25, 3692-704. [PubMed: 17296251]

(27). Jerome V, Graser A, Muller R, Kontermann RE, and Konur A (2006) Cytotoxic T lymphocytes responding to low dose TRP2 antigen are induced against B16 melanoma by liposomeencapsulated TRP2 peptide and CpG DNA adjuvant. J. Immunother. 29, 294-305. [PubMed: 16699372]

(28). Yoon YM, Lewis JS, Carstens MR, Campbell-Thompson M, Wasserfall CH, Atkinson MA, and Keselowsky BG (2015) A combination hydrogel microparticle-based vaccine prevents type 1 diabetes in non-obese diabetic mice. Sci Rep 5, 13155-13155. [PubMed: 26279095]

(29). Rockwood J, Dasu MR, Devaraj S, Jialal I, Griffen SC, and Winter W (2008) Increased Toll-Like Receptor (TLR) 2 and TLR4 Expression in Monocytes from Patients with Type 1 Diabetes: Further Evidence of a Proinflammatory State. J. Clin. Endocrinol. Metab. 93, 578-583. [PubMed: 18029454]

(30). Sutmuller RPM, den Brok MHMGM, Kramer M, Bennink EJ, Toonen LWJ, Kullberg B-J, Joosten LA, Akira S, Netea MG, and Adema GJ (2006) Toll-like receptor 2 controls expansion and function of regulatory T cells. J. Clin. Invest. 116, 485-494. [PubMed: 16424940]

(31). Hossain M, and Wall K (2016) Immunological Evaluation of Recent MUC1 Glycopeptide Cancer Vaccines. Vaccines 4, 25.

(32). Hossain MK, Vartak A, Sucheck SJ, and Wall KA (2019) Liposomal Fc Domain Conjugated to a Cancer Vaccine Enhances Both Humoral and Cellular Immunity. ACS Omega. 4, 5204-5208. [PubMed: 30949616] 
(33). Ferenbach D, and Hughes J (2008) Macrophages and dendritic cells: what is the difference? Kidney Int. 74, 5-7. [PubMed: 18560360]

(34). Rasche SS Processing and Presentation of Glutamic Acid Decarboxylase 65 T Cell-Inducing Epitopes: Implications in the Non-Obese Diabetic Mouse Model of Type 1 Diabetes, (2010), University of Toledo (http://search.ebscohost.com/login.aspx? direct=true \&db=ir00279a\&AN=oletd.toledo1290046839\&site=eds-live).

(35). Vartak A, and Sucheck SJ (2016) Recent Advances in Subunit Vaccine Carriers. Vaccines 4, 12.

(36). Hossain MK, Vartak A, Karmakar P, Sucheck SJ, and Wall KA (2018) Augmenting Vaccine Immunogenicity through the Use of Natural Human Anti-rhamnose Antibodies. ACS Chem. Biol. 13, 2130-2142. [PubMed: 29916701]

(37). Zhang L, Fu J, Sheng K, Li Y, Song S, Li P, Song S, Wang Q, Chen J, Yu J, et al. (2015) Bone marrow $\mathrm{CD} 11 \mathrm{~b}(+) \mathrm{F} 4 / 80(+)$ dendritic cells ameliorate collagen-induced arthritis through modulating the balance between Treg and Th17. Int. Immunopharmacol 25, 96-105. [PubMed: 25619457]

(38). Austyn JM, and Gordon S (1981) F4/80, a monoclonal antibody directed specifically against the mouse macrophage. Eur. J. Immunol. 11, 805-15. [PubMed: 7308288]

(39). Dos Anjos Cassado A (2017) F4/80 as a Major Macrophage Marker: The Case of the Peritoneum and Spleen. Results Probl. Cell Differ. 62, 161-179.

(40). Sarkar S, Salyer AC, Wall KA, and Sucheck SJ (2013) Synthesis and immunological evaluation of a MUC1 glycopeptide incorporated into 1-rhamnose displaying liposomes. Bioconjugate Chem. 24, 363-75.

(41). Gebe JA, Masewicz SA, Kochik SA, Reijonen H, and Nepom GT (2004) Inhibition of altered peptide ligand-mediated antagonism of human GAD65-responsive CD4+ T cells by nonantagonizable T cells. Eur. J. Immunol. 34, 3337-3345. [PubMed: 15549775]

(42). Boehm BO, Rosinger S, Sauer G, Manfras BJ, Palesch D, Schiekofer S, Kalbacher H, and Burster T (2009) Protease-resistant human GAD-derived altered peptide ligands decrease TNF-a and IL-17 production in peripheral blood cells from patients with type 1 diabetes mellitus. Mol. Immunol. 46, 2576-2584. [PubMed: 19505724]

(43). Alleva DG, Maki RA, Putnam AL, Robinson JM, Kipnes MS, Dandona P, Marks JB, Simmons DL, Greenbaum CJ, Jimenez RG, et al. (2006) Immunomodulation in type 1 diabetes by NBI-6024, an altered peptide ligand of the insulin B epitope. Scand. J. Immunol. 63, 59-69. [PubMed: 16398702]

(44). Walter M, Philotheou A, Bonnici F, Ziegler AG, and Jimenez R (2009) No effect of the altered peptide ligand NBI-6024 on beta-cell residual function and insulin needs in new-onset type 1 diabetes. Diabetes Care 32, 2036-40. [PubMed: 19690081]

(45). Cruz LJ, Rueda F, Cordobilla B, Simón L, Hosta L, Albericio F, and Domingo JC (2011) Targeting nanosystems to human DCs via Fc receptor as an effective strategy to deliver antigen for immunotherapy. Mol. Pharmaceutics 8, 104-116.

(46). Mercadal M, Domingo J, Petriz J, Garcia J, and De Madariaga M (2000) Preparation of immunoliposomes bearing poly (ethylene glycol)-coupled monoclonal antibody linked via a cleavable disulfide bond for ex vivo applications. Biochim. Biophys. Acta, Biomembr. 1509, 299-310. 

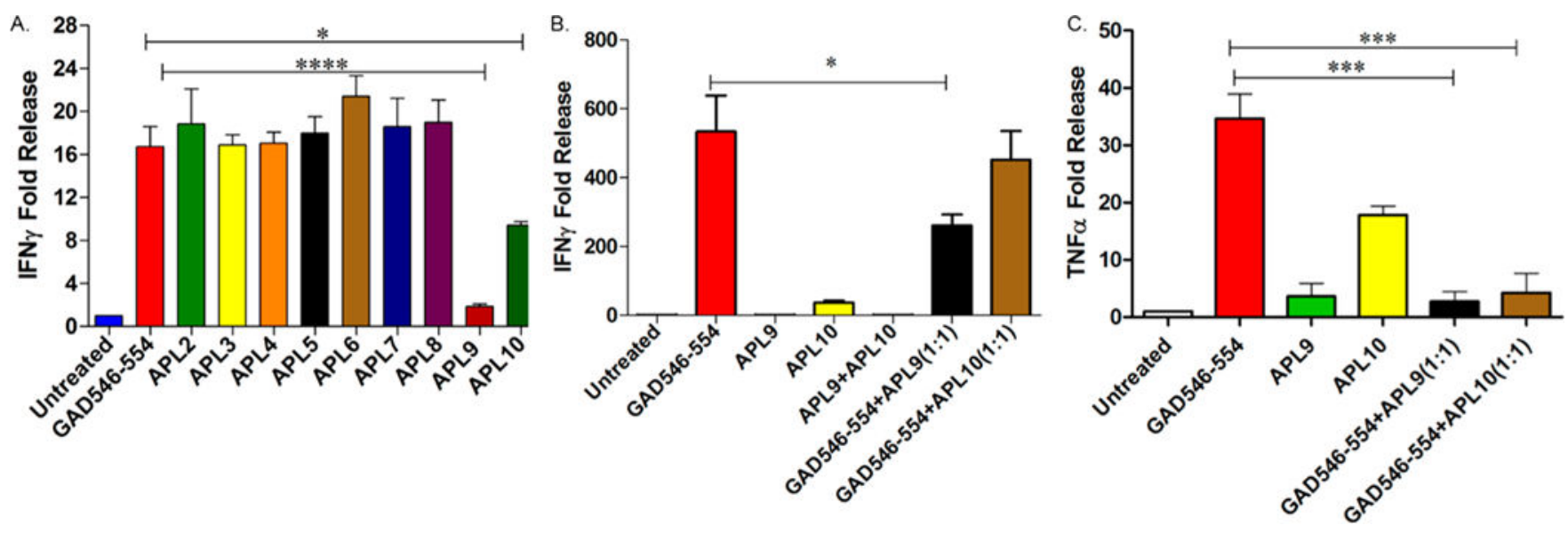

Figure 1.

Effect of GAD546-554 derived APLs on the CTL.546.L clone. (A) CTL.546.L clone cells were cocultured with irradiated M12C3.B7 cells pulsed with GAD546-554 or individual APLs derived from GAD546-554 and evaluated for IFN $\gamma$ release. (B) CTL.546.L clone cells were cocultured with irradiated M12C3.B7 B cells pulsed with GAD546-554, APL9, or APL10 or their combinations and evaluated for IFN $\gamma$ release. (C) CTL.546.L clone cells were cocultured with irradiated M12C3.B7 B cells pulsed with GAD546-554, APL9, or APL10 or their combinations and evaluated for TNFa release. One way ANOVA followed by Tukey's multiple comparison test were used: $n=3,{ }^{*} p \leq 0.05, * * * p \leq 0.001 * * * * p \leq$ 0.0001 . IFN $\gamma$ and TNFa release was normalized to untreated control. 


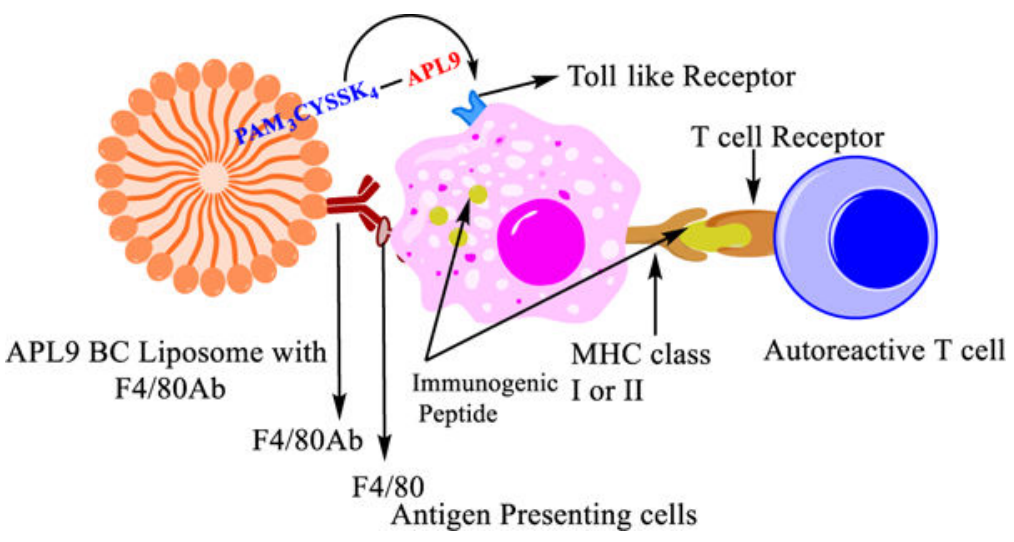

Figure 2.

Graphical illustration of bioconjugate liposomes developed for targeting autoreactive T cells in T1D. 


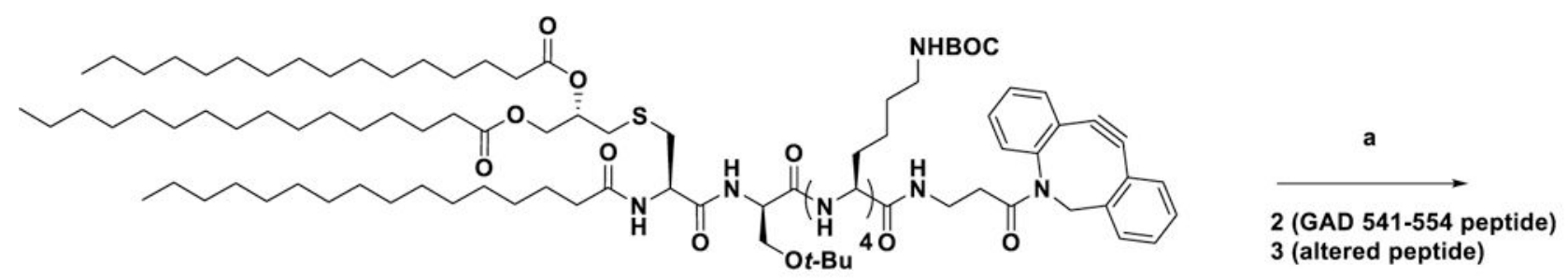

1

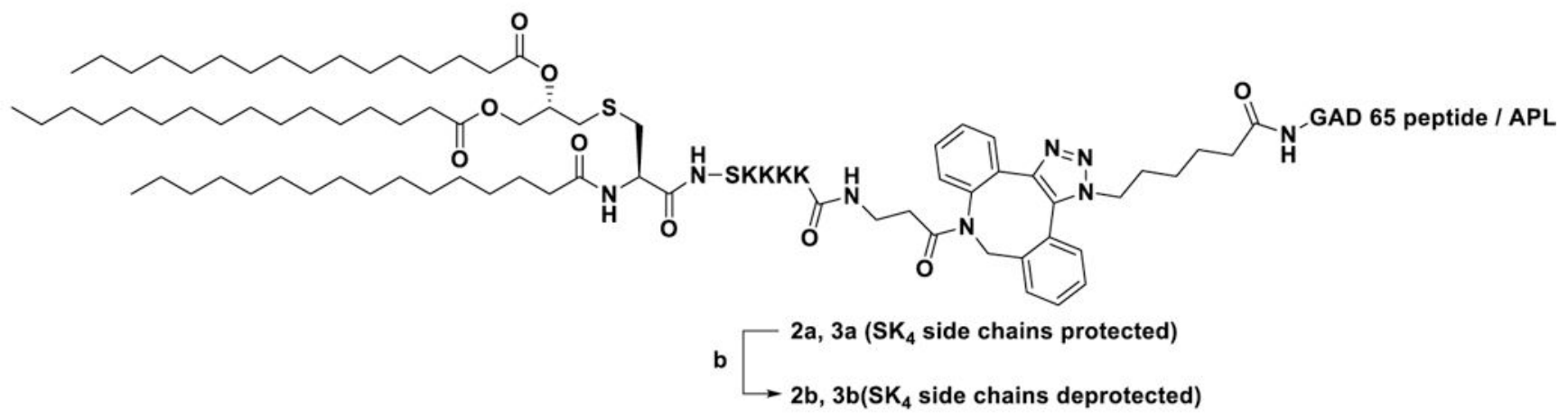

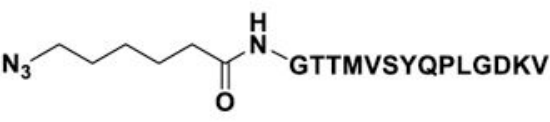

2 (GAD 541-554 peptide)

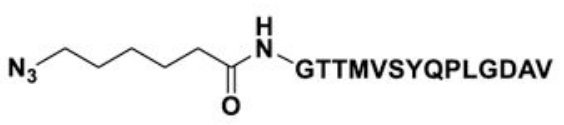

3 (altered peptide ligand)

Figure 3.

Synthesis of $\mathrm{Pam}_{3} \mathrm{CysSK}_{4}-\mathrm{GAD} 65$ peptide/APL conjugates. Reagents and conditions: (a) 1, MeOH-DCM (1:1), RT, 12 h, quantitative; (b) DCM:TFA:TES (50:50:0.5), RT, 40 min, 91$94 \%$. 


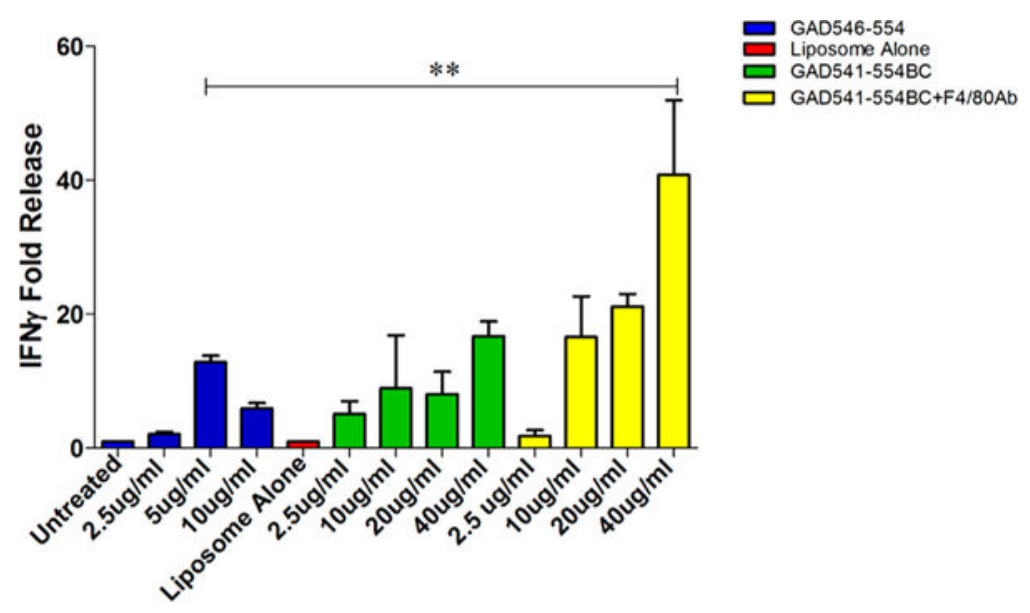

Figure 4.

Effect of GAD541-554BC with or without F4/80 Ab on CTL.546.L clone. CTL.546.L clone cells were cocultured with J774 cells pulsed with GAD546-554 peptide GAD541-554BC liposomes with or without F4/80 Ab and evaluated for IFN $\gamma$ release. One way ANOVA followed by Tukey's multiple comparison test were used: $n=3$, ** $p \leq 0.01$. IFN $\gamma$ release was normalized to untreated control. 

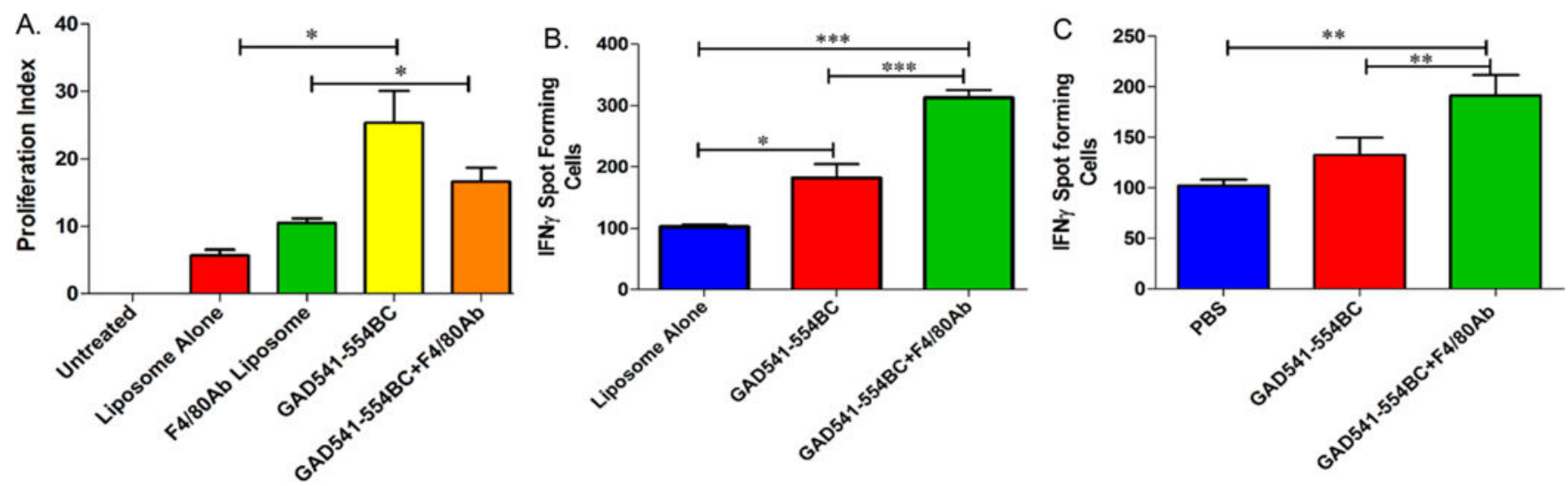

Figure 5.

GAD541-554BC with or without F4/80 Ab ex vivo and in vivo study. (A) Ex vivo evaluation of GAD541-554BC with or without F4/80 Ab on prediabetic NOD mouse splenocytes using CFSE treated proliferation assay. (B) Ex vivo study of GAD541-554BC on prediabetic mouse splenocytes using IFN $\gamma$ ELISPOT assay. (C) in vivo study of GAD541-554BC with or without F4/80 Ab in NOD mice. Six week old NOD mice were treated with GAD541-554BC with or without F4/80 Ab for three consecutive weeks and evaluated for IFN $\gamma$ secreting cells in treated mouse spleen at the end of 12 weeks of age. One way ANOVA followed by Tukey's multiple comparison test was used: $n=3, * p \leq 0.05$, $* * p \leq 0.01, * * * p \leq 0.001$. 


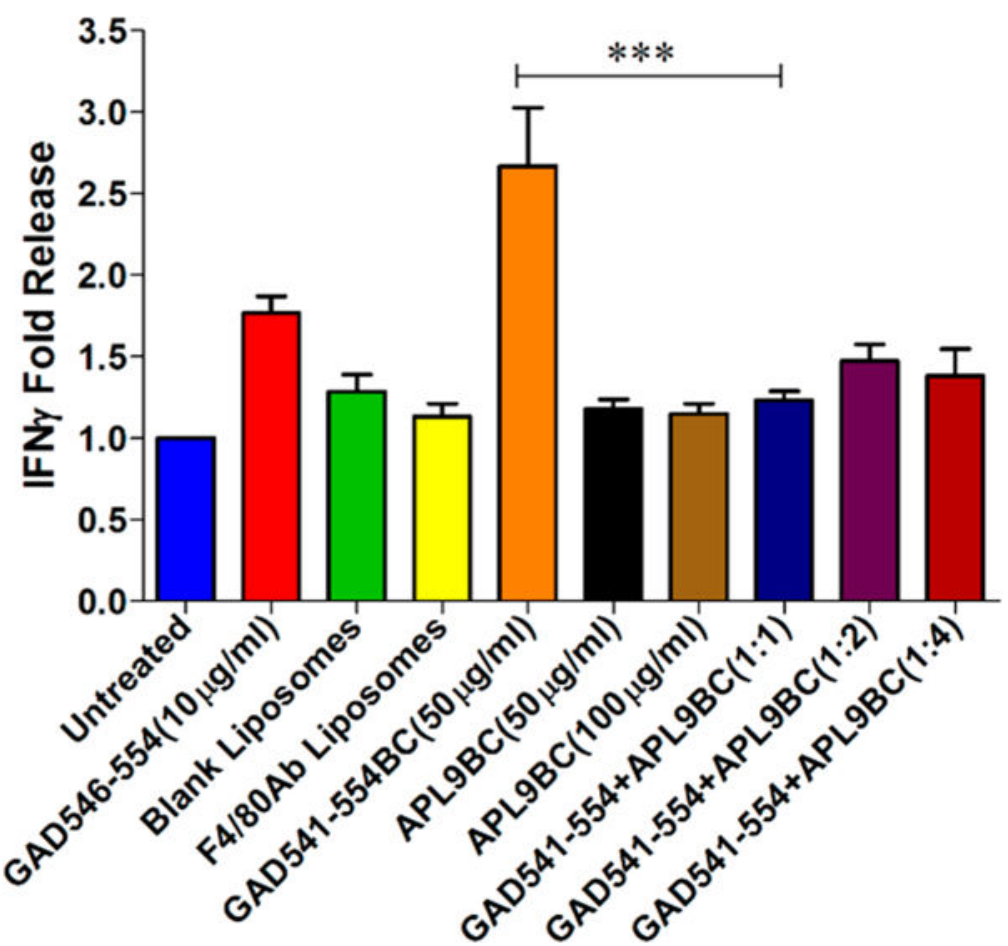

Figure 6.

Effect of GAD541-554BC+APL9BC liposome with F4/80 Ab on the CTL.546.L clone activity. CTL.546.L clone cells were cocultured with GAD541-554BC with F4/80 Ab (50 $\mu \mathrm{g} / \mathrm{mL})$, APL9BC with F4/80 Ab $(50 \mu \mathrm{g} / \mathrm{mL}$ or $100 \mu \mathrm{g} / \mathrm{mL})$, or a combination of GAD541$554 \mathrm{BC}$ with $\mathrm{F} 4 / 80 \mathrm{Ab}(50 \mu \mathrm{g} / \mathrm{mL})$ and APL9BC with F4/80 Ab $(50,100$, or $200 \mu \mathrm{g} / \mathrm{mL})$ pulsed J774 cells and evaluated for IFN $\gamma$ release. One way ANOVA followed by Tukey's multiple comparison test were used: $n=4, * * * P \leq 0.001$. IFN $\gamma$ release was normalized to untreated control. 
B. Islet without insulin secreting cells Islet with insulin secreting cells

A.

- Untreated

$\rightarrow$ F4/80Ab Liposome

- GAD541-554BC+F4/80Ab

$\rightarrow$ APL9BC+F4/80Ab

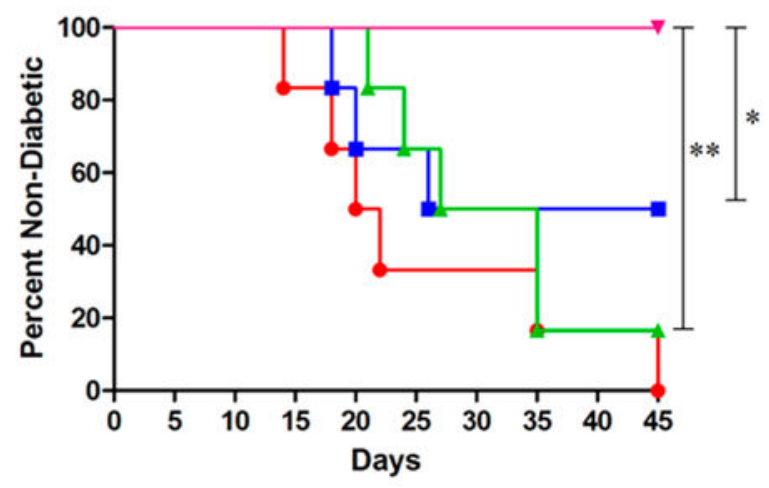

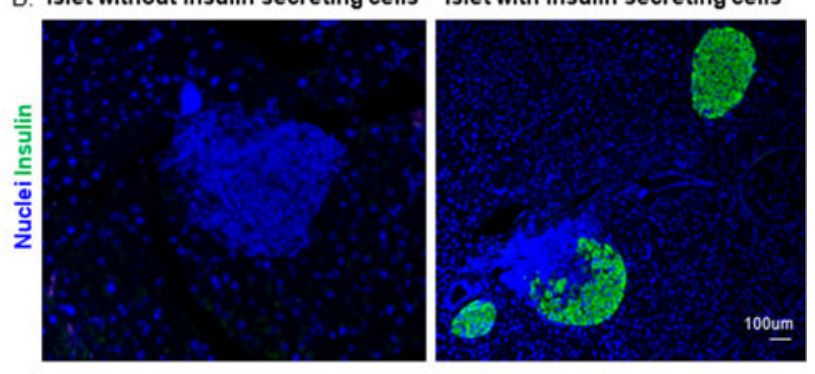

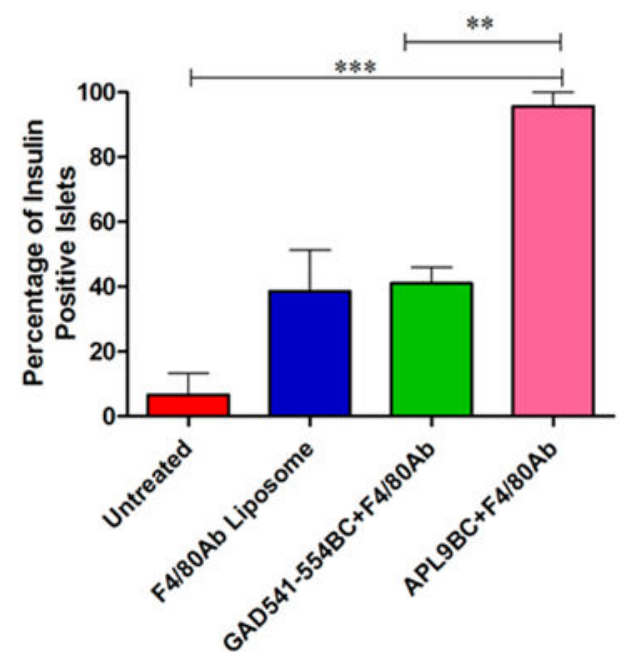

Figure 7.

Adoptive diabetes transfer experiment using bioconjugate treated diabetic splenocytes.

Twenty million recent diabetic female NOD mice $(n=4)$ splenocytes were treated with F4/80 Ab liposome or GAD541-554BC with F4/80 Ab (50 $\mu \mathrm{g} / \mathrm{mL})$ or APL9BC with F4/80

$\mathrm{Ab}(50 \mu \mathrm{g} / \mathrm{mL})$ and transferred into young irradiated NOD mice ( $n=6$ for each variable).

The positive control was left untreated. (A) Percentage of nondiabetic adoptive transfer recipient mice at the end of the experiment. Mice with a blood glucose level of $\geq 250 \mathrm{mg} / \mathrm{dl}$ were considered diabetic. Log-Rank analysis was used: $n=6, * P \leq 0.05$, $* * P \leq 0.01$. (B) Percentage of insulin positive islets determined based on the nuclei (blue) and insulin (green) labeling. One way ANOVA followed by Tukey's multiple comparison test were used: $n=3, * * P \leq 0.01, * * * P \leq 0.001$. 
Table 1.

List of APLs Screened for Developing Tolerance in CTL546.L Clone Cells

\begin{tabular}{cc}
\hline GAD546-554 & SYQPLGDKV \\
APL2 & AYQPLGDKV \\
APL3 & SAQPLGDKV \\
APL4 & SYAPLGDKV \\
APL5 & SYQALGDKV \\
APL6 & SYQPAGDKV \\
APL7 & SYQPLADKV \\
APL8 & SYQPLGAKV \\
APL9 & SYQPLGDAV \\
APL10 & SYQPLGDKA \\
\hline
\end{tabular}

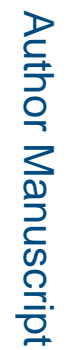

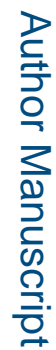

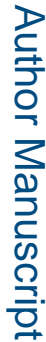

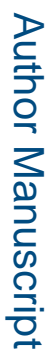

Bioconjug Chem. Author manuscript; available in PMC 2019 August 23. 